\title{
Neither Principles Nor Rules: Making Corporate Governance Work in Sub-Saharan Africa
}

\author{
Franklin Nakpodia $^{1} \cdot$ Emmanuel Adegbite $^{2} \cdot$ Kenneth Amaeshi $^{3} \cdot$ Akintola Owolabi $^{4}$
}

Received: 9 December 2015/Accepted: 11 May 2016/Published online: 23 May 2016

(c) The Author(s) 2016. This article is published with open access at Springerlink.com

\begin{abstract}
Corporate governance is often split between rulebased and principle-based approaches to regulation in different institutional contexts. This split is often informed by the types of institutional configurations, their strengths, and the complementarities within them. This approach to corporate governance regulation is mostly discussed in the context of developed economies and their regulatory demands. However, in developing and weak market economies, such as in Sub-Saharan Africa, there is no such explicit split and the debates on such contexts in the comparative corporate governance literature have been meagre. Nonetheless, there are sparks of good corporate governance practices in the region. Drawing from institutional theory and a case study of a largest economy, we explore the appropriateness or suitability of corporate governance regulatory frameworks in Sub-Saharan Africa. Our findings suggest that Nigeria needs an integrated system that combines elements of both rule-based and principle-based regulation, supported by a multi-stakeholder coregulation strategy. This paper departs from the mainstream
\end{abstract}

This article majorly constitutes a part in Nakpodia, F. (2016). An Assessment of Institutional Influences on Corporate Governance in Nigeria: A Multi-Stakeholder Perspective. Unpublished Doctoral thesis, Newcastle Business school, Northumbria University, UK.

Emmanuel Adegbite

e.adegbite@bham.ac.uk

1 Newcastle Business School, Northumbria University, Newcastle upon Tyne, UK

2 Birmingham Business School, University of Birmingham, Edgbaston, Birmingham B15 2TT, UK

3 University of Edinburgh Business School, University of Edinburgh, Edinburgh, UK

4 Lagos Business School, Pan-Atlantic University, Lagos, Nigeria rule-based and principle-based categorisations by forging ahead new perspectives on corporate governance regulation, especially in weak market economies.

Keywords Corporate governance - Sub-Saharan Africa (Nigeria) · Principles-based · Rule-based · Co-regulation · Institutional theory $\cdot$ Culture

\section{Introduction}

The suitability of corporate governance systems in different countries is mainly linked to the robustness of their underlying regulatory mechanisms (Shrives and Brennan 2015). Corporate governance systems are also often assessed on either principle-based or rule-based perspectives (Sama and Shoaf 2005; Arjoon 2006; Black 2008). Principle-based corporate governance codes are voluntary/ non-binding set of recommendations, standards, and best practices, issued by a collective body, in relation to the governance of corporations within a country (Chizema 2008; Osemeke and Adegbite 2016). Rule-based systems, however, create more avenues for government to intervene in corporate governance by coming up with stricter laws which must be adhered to (Adegbite et al. 2011). The literature on principle-based and rule-based regulations have mainly focused on understanding which of the regulatory approaches are better in different conditions (see Arjoon 2006; Benston et al. 2006). For instance, while Arjoon (2006) highlights the drawbacks of an excessive reliance on rule-based regulatory approach, Black (2008) explained that the global economic crisis of 2008 has exposed the failings of a principle-based regulatory approach.

In contributing to this debate, we note that the adoption of a principle-based or rule-based regulatory approach in a 
country is not necessarily informed by their inherent characteristics but the peculiarities of the institutional environment in that country. For example, Carmona and Trombetta (2008) indicated that accounting traditions and institutional conditions represent key variables influencing the adoption of a particular approach towards corporate governance regulation. This view is particularly important in examining the appropriateness of corporate governance regulatory approaches in Sub-Saharan African countries, which are challenged, amongst others, by weak corporate governance, poor disclosure and transparency, as well as fragmented relationships between shareholders and stakeholders (Okeahalam and Akinboade 2003; Okpara 2010).

However, what remains unknown is how corporate governance in sub-Saharan African economies should be regulated, especially in a country like Nigeria, where both rule-based and principle-based regulations are co-existing, and yet there is a lack of market confidence in corporate governance regulatory quality (Okike 2007; Inyang 2009; Osemeke and Adegbite 2016). Hence, we are guided by the research question: how should corporate governance in Nigeria be regulated?

Our focus in this paper is to explore the most suitable approach to corporate governance regulation in the largest African economy-Nigeria. The choice of Nigeria is informed by variety of factors. First, Nigeria is at the forefront of corporate governance research and development in Sub-Saharan Africa (Ahunwan 2002; Okike 2007; Amao and Amaeshi 2008; Amaeshi and Amao 2009; Adegbite et al. 2013); hence her corporate governance regulation is critical to the emergence of a robust corporate governance system within the Sub-Saharan African region. Second, the continued capacity of Nigeria and the region to attract investments is linked to necessary improvements in corporate governance regulation (Adelopo et al. 2009; Adeoye 2009). Yet, it is well documented that Nigeria is marred by weak corporate governance regulation and infractions (ROSC 2004; Okike and Adegbite 2012). ${ }^{1}$ However, previous studies have mainly stopped at highlighting some of these corporate governance regulatory challenges, without providing fundamentally new perspectives for regulating corporate governance in weak institutional contexts. This is what we offer in this paper. We present a model of regulation for corporate governance in developing economies which share economic and institutional characteristics similar to those of Nigeria.

Consequently, we make two principal contributions. The first proposes an alternative integrated approach for regulating corporate governance in Nigeria, whereas the second recommends co-regulation involving the government and

\footnotetext{
${ }^{1}$ Recent corporate governance failures in Nigeria include scandals at Cadbury, Unilever, Siemens, Haliburton as well as the banking crisis which led to the collapse of several banks (Okike and Adegbite 2012).
}

corporations in the country's corporate governance system. The insights we share regarding these are useful in understanding corporate governance regulation in different institutional contexts and help augment the nascent literature on corporate governance in Sub-Saharan Africa. The rest of this paper proceeds by reviewing relevant literature on corporate governance regulation to underpin our theoretical framework and our examination of the state of corporate governance in Nigeria. Thereafter, the methodology of this study is presented, followed by the discussion of our findings. We then summarise our key contributions and suggest some areas for future studies.

\section{Literature Review, Theoretical Underpinning, and Research Agenda}

Corporate governance does not only involve a set of relationships between a company's management, its board, its shareholders and other stakeholders, but also provides the structure through which the objectives of the company are set, and the means of accomplishing those objectives and monitoring performance are determined (OECD 1999, 2004). Given this broad understanding of corporate governance, one would expect that the attainment of such objectives requires an encompassing corporate governance regulatory framework. The task of developing such a framework is an important, yet difficult one. As Andreadakis (2008) questions, who will regulate the conduct of all the actors in the corporate governance field to ensure that predetermined goals are realised?

Regulation is central to the practice of corporate governance. Bruno and Claessens (2007) analysed a large number of corporations across different countries to understand how corporate governance practices in a company and the country's regulatory system interact to influence the company's valuation. While their study indicates that corporate governance plays an important role in ensuring efficient company monitoring and promoting corporate value, they show that the varying levels of regulation among countries informed the contrasting degree of corporate governance practices among countries (see also Roe 2003).

According to Just and Latzer (2004) as well as Cave (2013), corporate governance regulation can be viewed as occurring in a spectrum with four types including: Noregulation, self-regulation, co-regulation and statutory regulation (see Fig. 1). They propose that an appropriate regulatory framework must be established along this spectrum. Furthermore, the adoption of either principlebased (self-regulation) or rule-based (statutory) regulation must not only be in consonance with relevant institutional settings but should also fit with the regulatory strategy embraced in an institutional environment. 


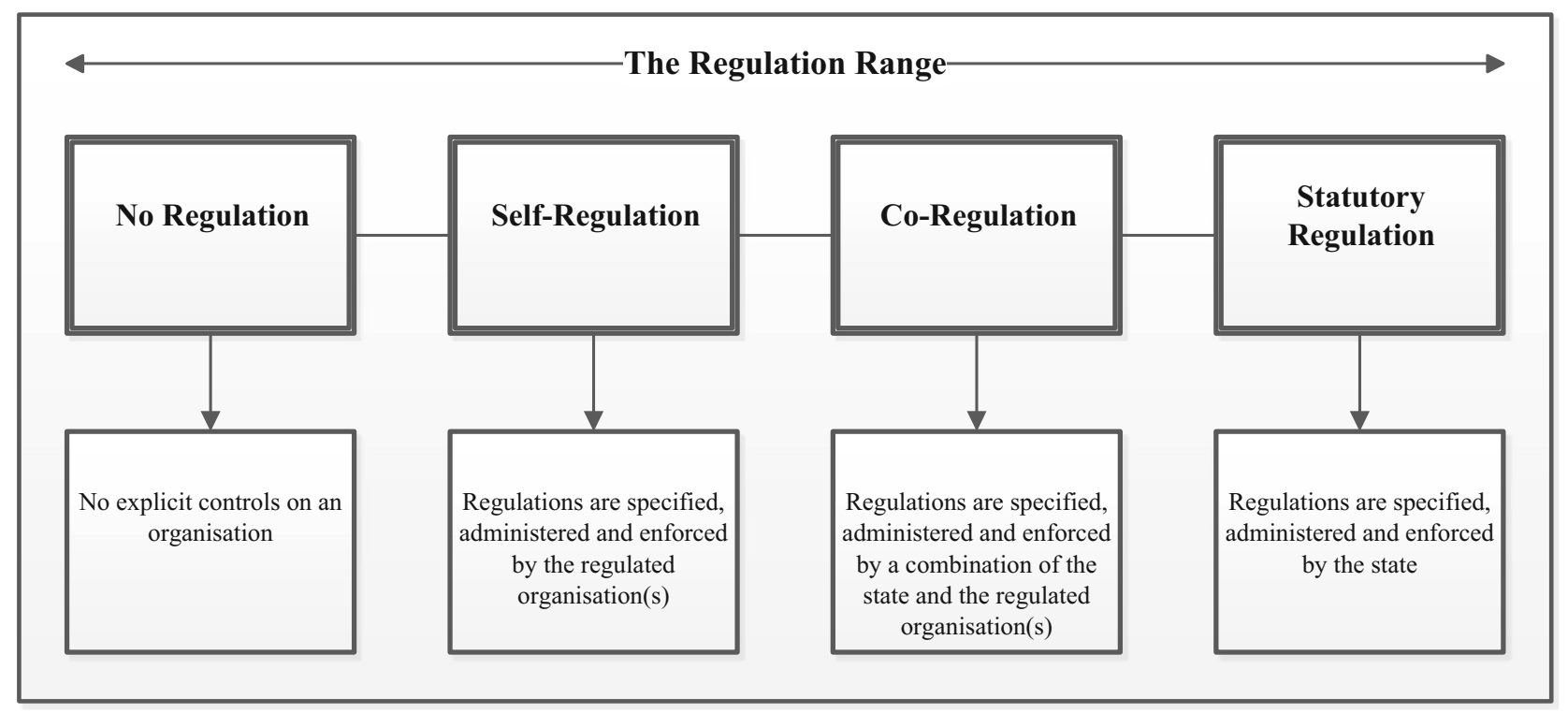

Fig. 1 Continuum of regulation. Source: Adapted from Just and Latzer (2004) and Cave (2013)

Accordingly, the country's institutional arrangements influence its corporate governance regulation (Aguilera and Jackson 2003; Filatotchev et al. 2013). While the agency theory has been considered as the supranational lens for evaluating corporate governance issues (Lubatkin et al. 2007), Guiso et al. (2009) contend that cultural and institutional specificities are generally omitted in the postulation of the agency relationship. However, institutional frameworks and efficiency are often embedded in cultures. In demonstrating the linkage between national cultures and institutions, Witt and Redding (2009) show that considerable variations in the rationale for defining the ideal structure of an economy between German and Japanese firms is informed by cultural effects on institutional elements. Furthermore, Tabellini (2008) noted that the functioning of institutions is influenced by individual values and convictions, which are outcomes of the dominant culture in an institutional environment. Similarly, findings in Guiso et al. (2006), Tabellini (2010) and Alesina and Giuliano (2015) suggest that institutions are substantial reflection of the main cultural disposition in an environment. Thus, culture is crucial to decisions regarding the adoption of either self-regulation (principle-based) or statutory regulation (rule-based) for corporate governance.

The rule-based approach, which provides the operating basis for Sarbanes-Oxley Act (2002) in the US, for example, directs that compliance is mandatory for operators (Sama and Shoaf 2005). Thus, companies are expected to obey the legal requirements or risk a penalty (Tricker 2015). Rule-based regulations are not only clear and certain, thereby limiting potential ambiguities; they are generally more operational than principles (Burgemeestre et al.
2009). Despite the strengths of this approach, Seidman (2004) noted that legal compliance with rule-based regulation results in ever-increasing bureaucracies, which although designed to enforce compliance, are often met by cynicism by operators and by clever employees who seek to undercut the system. Arjoon (2005) added that rulebased regulation may not necessarily instil excellence, largely because it is impossible for a particular legislation to address all possible human infractions.

Alternatively, the principle-based approach, such as in the UK, makes compliance voluntary (Black et al. 2007), such that companies are expected to either comply or explain where compliance cannot be achieved. Whilst the principle-based approach can be likened to a code of ethics, practitioners are still expected to justify the basis for actions taken, in order to avoid a reaction from the market. As this represents the capstone of the 'comply-or-explain' system (Shrives and Brennan 2015), the problem is that explanations are not always good enough as too much emphasis is placed on compliance with the requirement. Furthermore, Sun et al. (2010) reported that corporate managers in the UK use disclosure techniques to reduce the probability that public policy actions will be taken against their organisations. Black et al. (2007) also identified several concerns associated with the principles-based system to include lack of uncertainty, accountability issues, blurring of distinction between minimum standards and best practice, amongst others.

Notwithstanding the criticisms of these two regulatory approaches, the application of rule-based or principlesbased governance systems presents a fundamental concern, especially in the context of developing economies. This 
relates to the fact that both approaches are features of the Anglo-American cultural preferences expressed through the common law ${ }^{2}$ legal system. As such, can both regulatory approaches of corporate governance be applied in other legal jurisdictions (see Judge et al. 2008) with different socio-cultural preferences? Addressing this question, particularly in the context of Sub-Saharan Africa where there exists a "colonial' ${ }^{3}$ and 'translated" ${ }^{4}$ preference for civil law regimes, does provide an interesting proposition. Even in common law environments, which are based on case laws defined by precedents, can these case laws be relied upon in the poorly translated legal environments of Sub-Saharan Africa? Alternatively, can the use of both systems of corporate governance regulation compensate for the shortcomings of this legal institutional context?

Corporate governance regulation in Nigeria, for example, is statutorily entrenched in the Companies and Allied Matters Act (CAMA) (1990). Specific corporate governance regulation effectively commenced in Nigeria with the introduction of the Securities and Exchange Commission (SEC) Code (2003), which was principle-based and applied to all listed companies. However, despite the positives established by the Code, its implementation and enforcement were fraught with various challenges (Ofo 2010). Adegbite (2012) observed that the code relied on inputs developed and more relevant in other institutional climes. Adopting corporate governance guidelines which are best suited to western and less corrupt countries in a non-conducive environment can be ineffective (Soludo 2006; Okike 2007).

In their analysis, Adegbite and Nakajima (2011) conclude that the overall nature of the Nigeria's national and firm-level institutional environments are not complementary with good corporate governance principles in both national and corporate/industry levels. Furthermore, the peculiarity of the institutional environment was reinforced in Abdullahi et al. (2010), which examined regulatory responses to ethical abuses in Enron (USA) and Cadbury (Nigeria). They reported that whereas severe punishments

\footnotetext{
2 'Common law' refers to laws that are derived from custom and judicial precedent rather than statutes.

${ }^{3}$ It is important to highlight the influence of western colonisation on Sub-Saharan African economic and political institutions. It has been argued that these institutions are foreign to the region and sometimes conflict with the original socio-cultural preferences of sub-continent (Bräutigam and Knack 2004).

${ }^{4}$ Borrowing from the innovation diffusion literature (e.g. Djelic 1998), it can be argued that the 'modern' socio-economic institutions in Sub-Saharan Africa are translated, if not transposed, versions of western institutions. Given that these institutions are not home-grown they have continued to struggle to be embedded in Africa. A classic example is the case of democracy, as a form of government, which has not taken root despite over 60 years of political independence in most African countries (see Cheeseman 2015).
}

were meted out to those involved in the Enron scandal, same cannot be said in relation to Cadbury Nigeria owing to factors linked to the weak regulatory institutions and pervasive corruption levels. Munene (1995) also reports that the institutional environment in Nigeria is characterised by, among others, political patronage, dominant cultural disposition and high level of moral hazard. These weaknesses in the Nigerian institutional environment make corporate law enforcement and self-regulatory initiatives, for instance, perpetuated in idealism (Yakasai 2001; Ahunwan 2002).

However, global developments and issues encountered with the Nigerian SEC Code (2003) resulted in calls for a review of the code. A revised version of the code was released in 2011. It remained largely principle-based. Notwithstanding, in the intervening period (between 2003 and 2011), some sectors developed codes which sought to address the peculiarities of their respective industries (see Table 1). The first of such codes was the Central Bank of Nigeria (CBN) Code (2006), which was mandatory for banks; followed by the National Pension Commission Code of Corporate Governance for Licensed Pension Operators (2008) and the National Insurance Commission Corporate Governance Code (2008), which were largely principlebased.

Despite the comprehensiveness and numbers of these codes, there has been mounting criticisms against some of their provisions. For example, Adegbite (2012) noted that there is no clarity as to whether the SEC Code (2011) should be enforced as a rule-based or a principle-based code, thereby leading to confusion. Ofo (2011) also highlighted the confusion created by the disguised use of both approaches in corporate governance regulation in Nigeria. Furthermore, Osemeke and Adegbite (2016) have called for a combined corporate governance code due to the multiplicity, confusion, and inter-regulatory conflict in terms of compliance expectations with the existing different codes. However, the framework of corporate governance regulation in Nigeria needs to be significantly clearer to make a combined code effective in promoting firm compliance and better governance practices. There is also need to understand the challenges in embracing both rulebased and principle-based approaches to take advantage of the benefits inherent in both models.

Our research endeavour is informed by institutional theory (Judge et al. 2008; Filatotchev and Boyd 2009; Suddaby 2010). For our study, institutional theory helps highlight the critical interaction between institutions and individual self and character (Scott 2014). The theory contends that performance is linked to how institutions relate to individuals. This indicates that regulatory performance, for instance, may be better understood by exploring the association between legal institutions and the behaviour 
Table 1 Corporate governance codes in Nigeria. Source: Authors

\begin{tabular}{|c|c|c|c|}
\hline Corporate governance codes & $\begin{array}{l}\text { Year of } \\
\text { introduction }\end{array}$ & $\begin{array}{l}\text { Relevant } \\
\text { industry }\end{array}$ & $\begin{array}{l}\text { Principles-based } \\
\text { or rule-based? }\end{array}$ \\
\hline Securities and Exchange Commission (SEC) Code (replaced) & 2003 & All Industries & Largely principles \\
\hline Central Bank of Nigeria (CBN) Code & 2006 & Banking & Mainly rules \\
\hline $\begin{array}{l}\text { National Pension Commission (PENCOM) Code of Corporate Governance } \\
\text { for Licensed Pension Operators }\end{array}$ & 2008 & Pensions & Largely principles \\
\hline National Insurance Commission (NAICOM) Corporate Governance Code & 2009 & Insurance & Largely principles \\
\hline Securities and Exchange Commission (SEC) Code (revised) & 2011 & All Industries & Largely principles \\
\hline
\end{tabular}

of stakeholders. For instance, institutional theory predicts that the influence of performance is greatest when institutionalisation is low (Kraatz and Zajac 1996). 'Performance' as used in Kraatz and Zajac (1996) could represent variety of elements which include individuals. Therefore, employing the conceptualisation in Kraatz and Zajac (1996), the regulatory challenges in Nigeria, stimulated by the increasing influence of key stakeholders, might be explained by the weak legal institutions in the country. This development means that regulatory frameworks are exposed to the growing power and influence of key stakeholders. ROSC (2004) consented that institutional weaknesses represents a major challenge to corporate governance regulation in Nigeria. Generating insights into how corporate governance should be regulated in Nigeria will contribute towards addressing the foregoing concern.

\section{Methodology}

We adopted a qualitative, interpretivist approach. Here, we considered reality as the outcome of social construction and interaction (see Berger and Luckmann 1966). Consequently, we sought an understanding of corporate governance regulation in Nigeria based on the perceptions of key stakeholders in relation to institutional influences. The subjective perceptions of people helped to provide a rich and valuable source of information to our research inquiry (Bryman 2015). The differences in individuals and their corresponding perceptions therefore support the multiple reality view, which is consistent with the interpretivist research.

As such, it was crucial to identify a data collection technique that was consistent with qualitative and interpretivist studies. Patton (2002, p. 89) noted that there is a very practical side to qualitative (research) methods that simply involves asking open-ended questions of people ...in real-world settings in order to solve problems. This highlights the relationship between interpretive research and the use of interviews. Interviews allowed us to ask our research participants a series of questions which supported the collection of an in-depth and nuanced qualitative data (Denscombe 2010; Easterby-Smith et al. 2012).

In this study, in-depth interviews were conducted over a two-month period in the third quarter of 2013 using the semi-structured technique. Semi-structured interviews, according to Bryman (2015), refers to a context wherein the interviewer asks a series of questions that are in the general form of an 'interview guide,' but with the interviewer having the independence to vary the sequence of the questions. This approach, while encouraging a two-way communication, offered us more latitude to ask further questions as a reaction to what is considered a significant response. Thus information generated from our semistructured interviews did not only provide us answers, but also offered reasons for those answers (Flick 2014). Our methodology is consistent with previous studies on corporate governance regulation in Nigeria (Osemeke and Adegbite 2016).

On sampling and sample size, participants were drawn from the Nigerian business environment who were familiar with corporate governance regulation policies. They include corporate executives, regulators and corporate governance consultants. Executives (corporate board members) were selected from companies listed on the Nigerian Stock Exchange (NSE) and regulators were selected from some of the principal corporate governance regulatory institutions in Nigeria (NSE, SEC and the CBN). It is also important to highlight that sample size issues in qualitative research are often influenced by 'saturation, 5 concerns. A considerable volume of literature in qualitative research suggests that 'how many' is not what matters (Mason 2010; Burmeister and Aitken 2012). A researcher should therefore aim to satisfy himself/herself that he/she has learned, and understands the phenomenon, enough to

\footnotetext{
5 Saturation is achieved when the collection of new data does not shed any further light on the object being studied (Glaser and Strauss 1967). Saturation is fundamentally a grounded theory construct, however Mason (2010) suggested it can be adopted as a guiding principle during data collection.
} 
enable knowledge generation. This was our basis for determining sample size (see Pope et al. 2000; Mason 2010).

Given that the authors have substantial corporate and research experience in Nigeria, participants with the requisite profile were contacted via emails and telephone calls, outlining the research agenda. Regarding personal contacts, it is worth noting that Nigeria, according to Hofstede et al. (2010), is mainly a collectivist society. ${ }^{6}$ This opportunity allowed the authors to engage the snowballing technique, which proved beneficial in gaining access to high-calibre respondents (Denscombe 2010; Stigliani and Ravasi 2012). As a result, 21 interviews were conducted until saturation was achieved.

It is necessary to state that three stakeholder groups participated in this study namely corporate executives (denoted by 'E'), regulators (represented by 'R'), and corporate governance consultants, mostly academics (designated by ' $C$ '). The selection of these participants was informed by two main reasons. First, existing corporate governance regulations in Nigeria, especially the SEC Codes 2003 and 2011, have benefitted from the inputs of these three categories of respondents. Secondly, the desire to generate broad and rich insights regarding the study objectives compels the integration of a wide variety of stakeholders. The profiles of the participants are provided in Table 2.

The data collected for this study was analysed using the qualitative content analysis technique which allowed for the subjective interpretation of the content of text data through a systematic classification process of coding and identifying themes or patterns (Hsieh and Shannon 2005). Unlike the conventional (quantitative) content analysis, Schreier (2012) affirms that qualitative content analysis is not restricted to frequency counts. Rather, as Mayring (2000) suggests, qualitative content analysis provides a medium for exploring core themes. These features, in addition to its considerable link with interpretivist features (see Flick 2014) were crucial to its adoption in this study. Relying on a model proposed in Elo and Kyngäs (2008), we adopt a three step model to explore, classify and understand our data.

The first stage of our data analysis involved generating the sub-categories through making sense of the data, followed by an open coding procedure. This stage ensured that the many words of the transcribed material are classified into much smaller content categories (Weber 1990). This process generated themes which represent the subcategories, such as capacity of regulators, dearth of knowledge, cultural issues, as some factors which

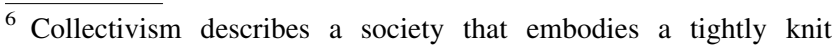
framework where individuals can expect their relatives or group members to provide for them in exchange for absolute loyalty.
}

undermine corporate governance regulation in Nigeria. The second stage of analysis involved the generation of generic categories where the sub-categories are grouped under higher order headings (Burnard 1991). The objective of this stage was to reduce the number of sub-categories by collapsing those that are similar or dissimilar into broader higher order categories (Dey 2003). In the final stage, an abstraction procedure was followed to generate an overall description of the research problem (Polit and Beck 2012). This stage resulted in the main category. "Appendix" presents the key themes that emerged from our data, which provide insights into our research inquiry on how to regulate corporate governance in Nigeria.

\section{Findings and Discussions}

Our data show that corporate governance regulation in Nigeria is fraught with inter-related challenges at both micro and macro levels, in line with institutional theoretical framework analysis. Macro-level factors describe the problems stimulated by societal distinctiveness, where corporate governance regulations have been impacted by morality and principle issues. The micro-level factors relate to the apathy and regulatory indifference which influence the attitude of key stakeholders towards regulations. We discuss these next, with supporting extracts from our anonymised data (E1-E9; R1-R8; C1-C4).

\section{Macro-level Issues: Societal Collective Moral Consciousness, Enlightenment and Perceived Colonial Culture Concerns}

As indicated in "Appendix", a generic category that emerged from the analysis, as a governance concern, relates to the belief system and moral principles of stakeholders-i.e. the societal collective moral consciousness and enlightenment. E7 noted that;

You know, the SEC code is driven by principles. I think this is where the problem lies. The use of principles will only work when the people are enlightened and display strong morals. But here in this country, most people are illiterate and poor, hence there is a lack of knowledge and a lack of awareness of corporate governance, and the capacity to remain morally upright is weak.

In addition, the challenge of corporate governance regulation in Nigeria is compounded by low literacy levels. As noted by E3;

The importance of corporate governance is not fully understood or well appreciated by the majority of 
Table 2 Profiles of participants

\begin{tabular}{llllll}
\hline Stakeholder group & \multicolumn{2}{l}{ Career background } & Total \\
\cline { 2 - 5 } & Law & Finance/accounting & Economics & Buss. \& Mgt & \\
\hline Corporate executives & 1 & 3 & 2 & 3 & 9 \\
Regulators & 2 & 2 & 1 & 3 & 8 \\
Consultants & 1 & 1 & 0 & 2 & 4 \\
Total & 4 & 6 & 3 & 8 & 21 \\
\hline
\end{tabular}

stakeholders. I think this has also lead to a situation where people are not really interested in corporate governance. I actually know some people who believe that pursuing corporate governance could create additional burden on their organisational finances.

Adegbite et al. (2012) infer that owing to low literacy levels, many shareholders are generally ignorant of their rights hence they prefer to remain passive (see also Uche et al. 2016). This increases the possibility of governance breaches by executives as the market fails to respond appropriately to their infractions. Indeed, in countries such as Nigeria, information asymmetry remains a concern (see Okpara 2010; Oyadonghan and Ogiriki 2014). This consequently undermines the robustness of a principle-based regulatory approach which relies on the market, to react to observed governance infractions.

Despite these interpretations, one could argue that these are collective manifestations of ill-suited Anglo-American culture of short-termism prevalent in the Nigerian system. E7 alludes to it;

The business community and in the country as a whole, we are short-term oriented. We are always focused on short-term gains. If (stakeholders) know that they will be disadvantaged in the short term, they would not engage in (infractions).

In relation to E7's comment above, R2, a regulator, added that;

I think the major problem of our regulation is that it bears the mark of our colonial masters. To be honest, when it comes to corporate governance, Nigerians perceive it differently compared to the British people. So, as long as these regulations largely resemble those of Britain, it is not likely to be effective for the people in this country.

Similar observations were noted by E3, E4, R5 and C3. Solomon (2013) argues that, from an institutional theory perspective, compliance with a code could be resisted, especially where the code originates from a foreign country with a different culture and environment. This resistance can result in 'decoupling." ${ }^{7}$ In essence, a code may not necessarily lack the capacity to address corporate governance concerns but institutional factors such as culture could undermine the functionality of the code. Rwegasira (2000) also emphasised that corporate governance, especially in African economies, will continue to experience challenges until measures are taken to adapt the governance model to acknowledge the peculiarities of specific economies. Indeed, comments from participants (E5, E8, R6, R7 and C4) indicate that some issues of governance in Nigeria border on the perception of corporate governance as a foreign concept. This concern emerges from the view that the codes are 'imported' from foreign countries, hence they lack the capacity to address, in particular, the cultural specificities of an ethnically diverse country such as Nigeria. E8 admits that;

... the problem of the codes is that they failed to integrate our own culture because it was imported from abroad. So people will not identify with it. These codes do not address our local cultural peculiarities.

Participants were unanimous in suggesting that the practice of corporate governance in Nigeria has been hampered by this development. In addition, morality and principles are also impacted by the dominant cultural affiliations of stakeholders. For instance, whereas C3 stated that "you cannot separate people from their culture", E6 commented that;

Culture ...plays a very significant role in all that we (Nigerians) do. Our culture determines how we accept and react to issues, even economic issues. I personally think our cultural values and affiliations bear the greatest impact on the actions of at least, the majority of Nigerians.

In corporate governance discourse, there is evidence (Haniffa and Cooke 2002; Licht et al. 2005) to suggest that

\footnotetext{
${ }^{7}$ Decoupling' describes where actual behaviour of members of an organisation frequently does not reflect official accounts (Scott 2014). There is apparent compliance with codes, but there is no genuine organisational change in practice (Solomon 2013). A participant described this development as 'technical compliance'.
} 
corporate governance has been influenced by a dominant culture. Similar conclusions have been reported in Nigeria. Oghojafor et al. (2012), whilst describing the relationship between corporate governance and national culture as $\mathrm{Si}$ amese twins, noted that national culture plays a crucial role in the efficacy of corporate governance. Some other works (Ite 2004; Amaeshi et al. 2006) suggest that the implication of culture upon corporate governance practices in Nigeria is substantial. This view was alluded to by a majority of the participants, as they indicated that culture has strong implications for corporate governance in Nigeria. However, the majority of the participants opined that the dominant cultural values in contemporary Nigerian society are not consistent with the principles of corporate governance.

\section{Micro-level Issues: Individuals' and Firms' Apathy and Indifference to Regulations and Practice of Regulatory Avoidance}

The foregoing contributes to the general apathy of stakeholders towards regulations. Participants indicated that problems bordering on compliance and enforcement of regulations, the regulatory power of regulators, political influence, corruption levels and the ability to manipulate the legal system by influential stakeholders have heightened the apathy and indifference of operators towards regulations. E1 highlighted the challenge that emerges when stakeholders show apathy towards regulations. This challenge was noted in Ahunwan (2002). C1 explained that;

From my experience, it is widely known that many so-called operators have never really sat down to look at the SEC code even the 2003 version. As a result, they don't even know what is expected of them and cannot perform.

Furthermore, there are inherent challenges at the microlevel, especially with reference to the ability of individuals and firms to undermine compliance and enforcement through corrupt practices. R1 explained that;

It is far too easy to avoid compliance in this country as long as the individual or organisation is willing to offer gratification. You know, same thing also applies to the enforcement strategies for corporate governance. Generally, enforcement of the regulation is weak and there is no accountability. There are actually cases where regulators also help to facilitate these problems.

Emenyonu (2007) traced the emergence of the issues raised by $\mathrm{C} 1$ and $\mathrm{R} 1$ to micro-institutional deficiencies which have subsequently given rise to a growing number of
Nigerians who are able to ignore the provisions of the country's laws to perpetrate corporate corruption. As the foregoing perception suggests that Nigerians display apathy towards regulations, Adegbite (2012) added that the weaknesses in regulatory institutions have been exploited by individuals and firms to create this attitude. Okpara (2011) agreed that a strict enforcement regime is likely to force compliance. This is consistent with the view of R6;

The code should be made mandatory (with the) introduction of stronger enforcement mechanisms, (fortified) with (tougher) sanctions.

Thus, whilst the use of regulations has appeared ineffectual, it is possible that a sound regulatory regime, strengthened with commensurate enforcement strategies, could change the attitude of Nigerians at the micro-level towards regulatory policies. Thus, a rule-based system with an appropriate sanction strategy might generate better results, as it minimises the possibility for misinterpretation and misunderstanding (Sama and Shoaf 2005) at the microlevel.

Furthermore, the desire to circumvent regulations and pursue economic alternatives that would yield financial benefits for operators reflects a desire to achieve, but only in the short term. The adoption of a principle-based approach could accelerate short-termism, as it allows firms to seek voluntary compliance to corporate governance codes (Adegbite 2012).

A participant (E4) also noted the prevalence of 'technical compliance' rather than substantive compliance amongst Nigerian organisations, observing that;

You can always secure technical compliance with corporate governance by satisfying the (requirements) but there is still a long way to go in adopting the underlying values and principles which drives corporate governance. For instance, it is easier to find a director who satisfies the definition of "independent" but is he really independent?

Technical compliance suggests an adherence to the letter of the code but as Sama and Shoaf (2005) observe, technical compliance inadvertently undermines the promotion of the very spirit of the code - a classic case of regulatory avoidance. Consequently, in such environments, adherence to 'soft laws' (Black 2008) is bound to experience challenges. This was supported by $\mathrm{C} 2$;

I do not see a principle-based regulation working in this country. At least not now. The behaviour of many Nigerians will not allow the use of principlesbased regulation to succeed. A strict sanction strategy, which you may liken to rules, will be more (appropriate). In my opinion, that is what we need. 
These concerns provide the rationale for exploring the rulebased and the principle-based approaches to regulation in the context of Nigeria.

\section{Neither Principles Nor Rules: Which Direction for Nigeria?}

From the two generic categories discussed above, there is a need to modify the regulatory mechanism for corporate governance in Nigeria. Though the Anglo-American system has influenced the regulation of corporate governance in Nigeria, the model appears to be specifically suited to systems where institutional frameworks are robust enough to check the behaviour of economic actors. As previously noted, the control of corporations is influenced by social relations and existing institutional arrangements (Aguilera and Jackson 2003). Thus, the institutional environment must be accounted for prior to and during the establishment of corporate governance systems in developing economies (Rwegasira 2000).

In addition, Mangena et al. (2012) demonstrate that the performance of a corporate board, for example, is dependent on the firm's environment. A firm's environment tends to reflect the dominant national culture. This suggests that the search for a suitable corporate governance system must integrate cultural distinctiveness. Thus, in countries such as Nigeria, the regulation of corporate governance must be established and implemented based not only on an understanding that such regulatory interventions must not only recognise the peculiarities of the institutional environments but also its main cultural influences.

Consequently, such regulatory intervention must not only have the capacity to tackle the concerns identified in the sub-categories (see "Appendix"), but must be robust and enduring, in order to address corporate governance concerns over the long term. Ofo (2010) traced the origin of the governance problem in Nigeria to the lack of a distinct regulatory system. In the SEC Code (2011), Ofo (2011) noted that the inability of regulators to clearly position the code either as a rule-based or principles-based regulation creates misunderstanding and confusion in the application of the code by stakeholders. While the SEC Code (2011) notes that it aims to ensure that its provisions are enforceable, it further indicates that;

The code is not intended as a rigid set of rules. It is expected to be viewed and understood as a guide to facilitate sound corporate practices and behaviour (Section 1.3a).

It can be claimed that the view above is significantly indicative of a substantial leaning towards a principlesbased approach. One can therefore argue that even as the SEC Code has a preference for a principles-based regulation, there is an understanding that this may not lead to desired compliance and governance standard. Schwarcz (2009) posits that principle-based regulation is thought to more closely achieve normative goals than rules, but added that the extent to which this occurs depends on the enforcement strategy. In Nigeria, Adegbite (2012) noted that regulation and enforcement are at variance. This position is consistent with the views of the majority of participants.

We previously highlighted the problem with a principlebased regulatory approach, stressing that the prevalent low levels of morality and literacy as well as high poverty levels have meant that issues of ethics and morality are constantly challenged, especially in view of its normative nature and intangibility. These issues informed R8's comment;

Principle-based (regulation) may not work in Nigeria. The institutional environment does not support it. It is difficult to do business (in Nigeria) based on principles.

This suggests that principle-based regulation may lack the capacity to foster the entrenchment of a robust corporate governance system thus compelling the development of an alternative regulatory strategy. An alternative will be rulebased strategy or the stick approach (Arjoon 2005). There is a consensus among stakeholders noting that corporate governance compliance and enforcement in the Nigerian banking sector have been commendable, owing substantially to the CBN's regulatory approach. Indeed, whereas E7 noted that 'sectors such as the banking sector have a higher level of compliance,' the reason for this development, as observed by E5 is connected to the fact that corporate governance regulation in the banking industry is mandatory. $\mathrm{C} 1$ reinforces this view;

We can argue that the banks in Nigeria have the best corporate governance practices because of the CBN code of 2006 which is essentially rule-based.

E2 also commended the CBN for the improvement of corporate governance among banks in Nigeria, agreeing that the banking sector in the country is where the benefit of effective corporate governance is most evident. Section 1.7 of the CBN Code (2006) stipulates that:

Compliance with the provisions of this Code is mandatory.

Clearly, the CBN Code, unlike its SEC counterpart, adopts a rule-based regulatory strategy. The relative success recorded in the banking sector with respect to corporate governance (see Odeleye 2014) suggests that Nigerian firms and stakeholders are more responsive to rules than principles. In addition, the economic importance of the 
banking system, which demands a stringent oversight and intervention by the government, may have informed the relative achievements with regard to the $\mathrm{CBN}$ code.

In view of the above, it is proposed that corporate governance regulation must substantially reflect a rulebased approach. In other words, substantial elements of the existing code should be updated to exhibit a rule-based mechanism. There are benefits of pursuing this alternative. First, if urgent steps must be taken to address the significant governance challenges in the country, a rule-based regulatory system has been acknowledged to offer an attractive reform strategy, especially in the short-term (Benston et al. 2006; Kim and Saito 2009). Thus, a rule-based approach can be engaged as a "quick fix" to reposition governance practices, in order to enhance its capacity to earn the benefits of good corporate governance. This recommendation is linked with the need to increase awareness of corporate governance and to communicate a strong signal that regulations are to be adhered to. As was the case with the introduction of the CBN Code (2006), a substantially rule-based regulation can drive corporate governance awareness as operators increasingly desire to avoid exposure to stiffer penalties.

Drawing from the foregoing, it is crucial to note that the success of a rule-based mechanism is enhanced by the extent to which sanctions are enforceable (Sama and Shoaf 2005). Thus, this study also proposes "certainty of enforcement". Regulators must desist from setting aside the enforcement mechanism for governance infractions perpetrated by operators. The inability and lack of capacity (on the part of regulators) to punish offenders have been consistently highlighted as a major setback for corporate governance regulation in many developing economies. Therefore, legal loopholes which can be exploited by operators must be identified and addressed to minimise the potential of "exit" from prosecution. Certainty of enforcement will also promote deterrence (Becker 1974). In an institutional context with limited regard for principles, sanctions must be severe enough to discourage infractions and unethical practices (Akers 1990; Ellis 2003). Black (2008) explained that with deterrence-based approaches, tough and formal enforcement actions become the norm. Therefore, sanctions must be designed such that the benefits gained by engaging in governance infractions cannot compensate for the penalty (Ellis 2003). Many operators indeed undertake "cost-benefit analysis" before reaching a decision to engage in ethical (or unethical) practices. As such, the penalties need to be substantial in order to encourage compliance.

However, we argue that it is difficult to realise the longterm objectives of a robust corporate governance system relying on a single approach. Despite the preference for a rule-based regulation, this study recommends that the new regulatory model must incorporate elements of the principle-based approach, thereby integrating relevant elements of both approaches in a regulatory framework. This proposition is to enable it take advantage of the benefits inherent in a principles-based regulation which include allowing for social sanctions to act as deterrents to unethical conduct (Sama and Shoaf 2005), the broadening of the legal boundaries to issues not addressed by law (Arjoon 2006) and the emphasis on substantive compliance and less on box-ticking or working out how to avoid rule in substance (creative compliance) (Black 2008). This is crucial because rule-based, as proposed, is intended to offer a short-term impact. The pursuit of good corporate governance is a "journey" (Madhani 2007) and the objective must be to achieve good corporate governance in the longterm. Arjoon (2005) stated that legal compliance, which is the basis of a rule-based approach encourages letter of the law which may not inspire excellence, but ethical compliance which underlies principles-based approach promotes the spirit of the law. Arjoon (2006) added that principles-based regulation tends to be value-driven, focuses on prevention and develops over the longer term.

Further reasons why an integrated framework is suggested is that the nature of a rule-based system cannot account for every possible infraction. A system centred on principles possesses the mechanism to manage more seemingly silent activities of humans as it relies on morality, ethics and value. Whereas Trevino and Nelson (2010) acknowledge this point, Sama and Shoaf (2005) note that principles such as impartiality, transparency, accountability, responsibility, truthfulness and respect for rights are broader than the law, and hence may not be accounted for in a rule-based system. The principles noted in Sama and Shoaf (2005) are critical to an enduring corporate governance system, hence a principle-based approach must necessarily be incorporated in any corporate governance regulatory framework. Therefore, whilst noting that the institutional environment in Nigeria does not support complete dependence on the principles-based or rule-based approaches, an appropriate mix of both approaches can generate better outcomes. C4 noted as follows:

I see rule-based as a quick fix. Principles-based are the best and more sustainable but it takes a long time for its results to lead to real change in behaviour. Maybe policy makers should be considering how to use both (approaches).

C1 further highlights the complementarity of both approaches;

... You know rules cannot (address) every issue. Rules will only be able to attend to simple issues, but 
with principles you can attend to all issues whether complex or simple. (which is only possible when stakeholders) have internalized the (principles).

In line with the foregoing, we proceed to discuss the implementation strategies of the integrated regulatory approach on the basis of a multi-stakeholder co-regulation framework.

\section{Further Discussions}

\section{Implementing An Integrated Regulatory Approach}

In this paper, we propose a shift from the present principlebased regulatory structure of corporate governance in Nigeria to a substantially rule-based approach. However, this must follow a precise implementation pattern represented in Fig. 2, which reveals three phases towards the establishment of an integrated regulatory approach. The first phase proposes an entirely rule-based regulatory framework whereas in the second phase, core elements of principle-based regulation are gradually incorporated into the existing regulatory framework. In the final phase, the regulation increasingly reflects a principles-based regulation.

In relation to the above, Black (2008) agreed that adopting a principles-based or rule-based approach as an extreme position is a suboptimal strategy to implement. But Apampa (2014) questioned if a hybrid (a mix of principles-based and rule-based) model is deemed appropriate, and where along the spectrum should the optimal strategy lie? This is an important query which implies that regulators should first seek to negotiate with operators towards a consensual optimal strategy (Black 2008). However, if this strategy does not yield expected compliance levels, regulators should gradually move up the enforcement pyramid whilst applying sanctions of increasing severity (Black 2008). This process must continue until compliance levels are acceptable. It might then be appropriate at this stage to embark on the second phase (see "Appendix") which will entail the introduction of more sustainable, principles-based regulatory approach. This procedure signifies that the existing regulatory approach will continue to change positions on the spectrum until the desired outcomes are visible.

In the third phase in Fig. 2, the regulatory system will gradually move from being a substantially rule-based mechanism to a considerably principles-based regulation. This strategy is proposed considering that principles-based regulation not only emphasises a long-term view but also possesses the capacity to address issues which lie beyond the boundaries of a rule-based regulatory system (Sama and Shoaf 2005; Arjoon 2006). The movement from one phase to another must be the outcome of an assessment of corporate governance by relevant stakeholders at different points in time.

The Netherlands and South African corporate governance systems offer evidence of the potential of an

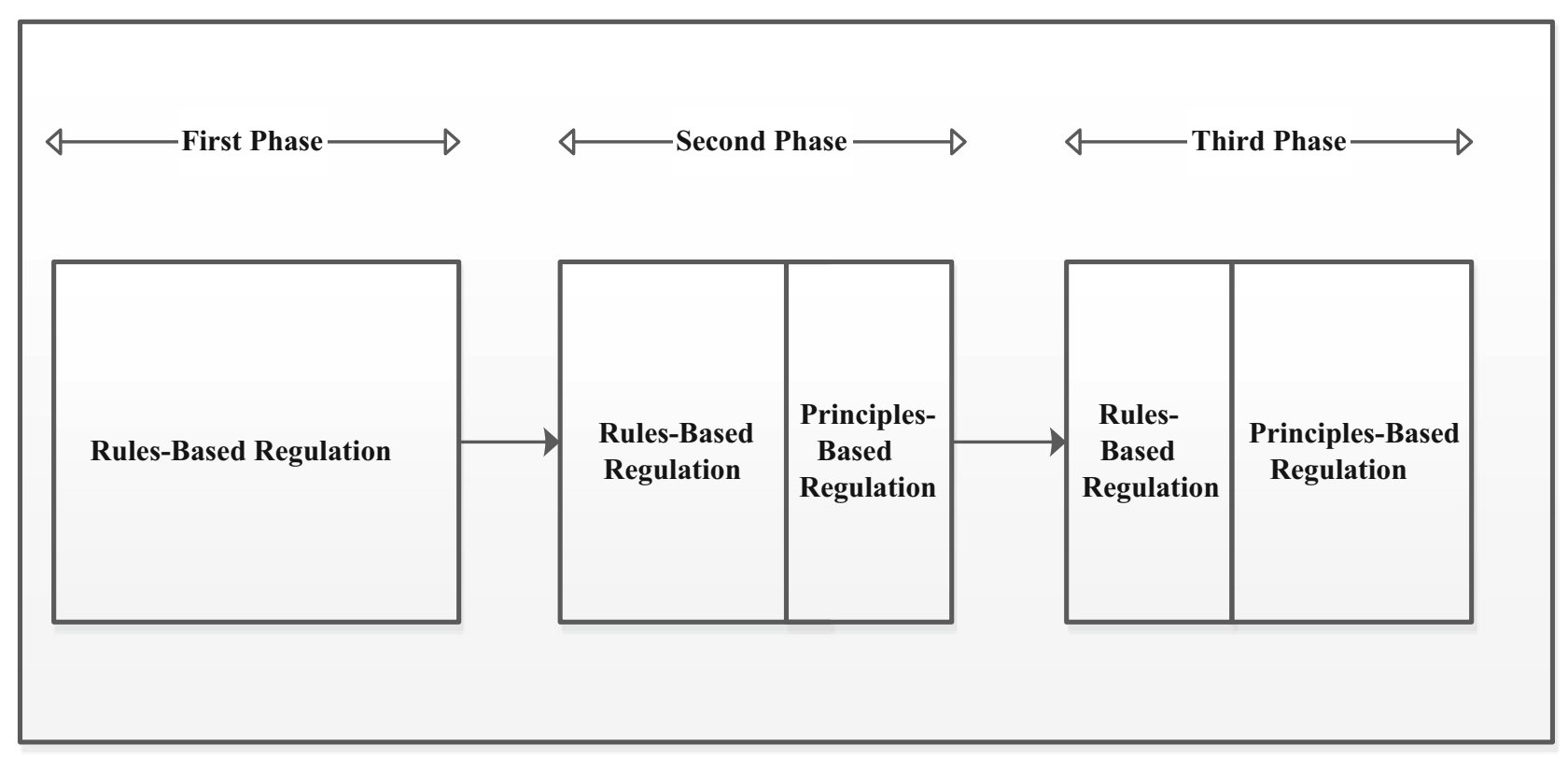

Fig. 2 The integrated regulatory approach. Source: Authors 
integrated regulatory approach. In South Africa especially, the Kings Report III opted for an 'apply or explain' regime (Institute of Directors SA 2009) rather than the conventional 'comply or explain' system. This is because the 'apply or explain' system acknowledges that it is not a case of whether to comply or not, but emphasises how the principles can be applied. Notably, the Institute of Directors SA (2009) admitted that in an 'apply or explain' regime, principles override specific recommended practices but added that some principles have been legislated which compels compliance with the letter of the law and removes the incidence of subjective interpretations. Thus, whereas the foregoing offers evidence that the 'apply or explain' approach integrates the elements of rule-based and principles-based approaches, it crucially gives some power to corporate boards. For instance, where a board believes it is in the best interest of the company, it can adopt a practice different from that recommended by King III but the practice must be explained. According to the Institute of Directors SA (2009), the change became necessary to address peculiarities of the South African business environment. This reinforces the view that countries should pursue policies which serve their best interest. Hence, it is proposed that a rule-based system be established in the Nigerian code, in the short term. Subsequently, a principles-based regulatory regime must be gradually integrated into the framework. In this study, the regulatory framework integrating elements of the principles-based and rule-based approaches is regarded as the integrated approach to corporate governance regulation.

\section{A Multi-stakeholder Co-Regulation Strategy}

Having recommended a regulatory approach for corporate governance in Nigeria, it is necessary to offer further insights that would enhance the functionality of the proposed integrated regulatory framework. Generally, regulations, according to Adegbite (2012), are produced by agencies with the commensurate power and authority to induce compliance by operators. As a result, regulations could be viewed by operators as unfair owing substantially to their coercive nature. This perception tends to have consequences for compliance. This challenge is more pronounced in a country like Nigeria where the government has been repeatedly accused of not abiding by the provisions of existing regulations, thus providing a rationale for corporations to also seek ways (albeit illegitimate) to evade compliance. The nature of this challenge in the Nigerian business environment dictates that an alternative strategy be proposed for the integrated regulatory approach to achieve desired objectives.

Co-regulation involves a system wherein government and firms share responsibility for drafting and enforcing regulatory standards (Hirsch 2011). Co-regulation is neither purely a government regulation nor purely an industry self-regulation, but a hybrid of both (Hirsch 2011). Kirkbride and Letza (2004) suggested that corporate governance regulation has taken a significant new direction. They explained that the boundaries of regulation are no longer determined by the choice between market-based (self) regulation and state-based (statutory) regulation but by a process of collibration. ${ }^{8}$ The benefit of this approach, according to Hirsch (2011), is that it ensures collaboration between government and businesses, leading to improved government-industry relationships, making both units problem-solvers.

However, the general view of co-regulation focuses mainly on cooperation between companies and government. Whilst this form of co-regulation is termed 'cogovernance' or 'collaborative governance' (Hirsch 2011), this paper proposes a multi-stakeholder form of co-regulation, which implies the relationship between business and its stakeholders in developing corporate governance regulation (Albareda 2008). This expands the frontier of corporate governance regulation beyond businesses and government. The main rationale for the proposed regulatory strategy is informed by concerns regarding the industry-government relationship which occurs beyond the public view. This could yield one-sided outcomes which fail to protect other stakeholders (Hirsch 2011).

We present our model to frame co-regulation for corporate governance in Nigeria in Fig. 3. The model indicates that dialogue between businesses and stakeholders generates a negotiated regulation which is consistent with the expectations of the parties involved. This ensures joint responsibility amongst stakeholders in administering and enforcing corporate governance regulations.

\section{Summary}

In this paper, we have examined the existing regulatory approach for corporate governance in Nigeria. We acknowledge that corporate governance regulation in Nigeria has been pursued largely using the principle-based approach. Our discussions reveal that some of the problems of corporate governance in Nigeria, such as corruption, the cultural belief system and the dearth of knowledge, among others, are inconsistent with the application of principles. The adoption of a principle-driven regulatory approach is enhanced where information flows freely in the system and

\footnotetext{
${ }^{8}$ Collibration describes the process of government intervention in order to recognise a balance between its objectives and those of the market with a view to managing the balance such that government policy objectives are realised (Kirkbride and Letza 2004).
} 


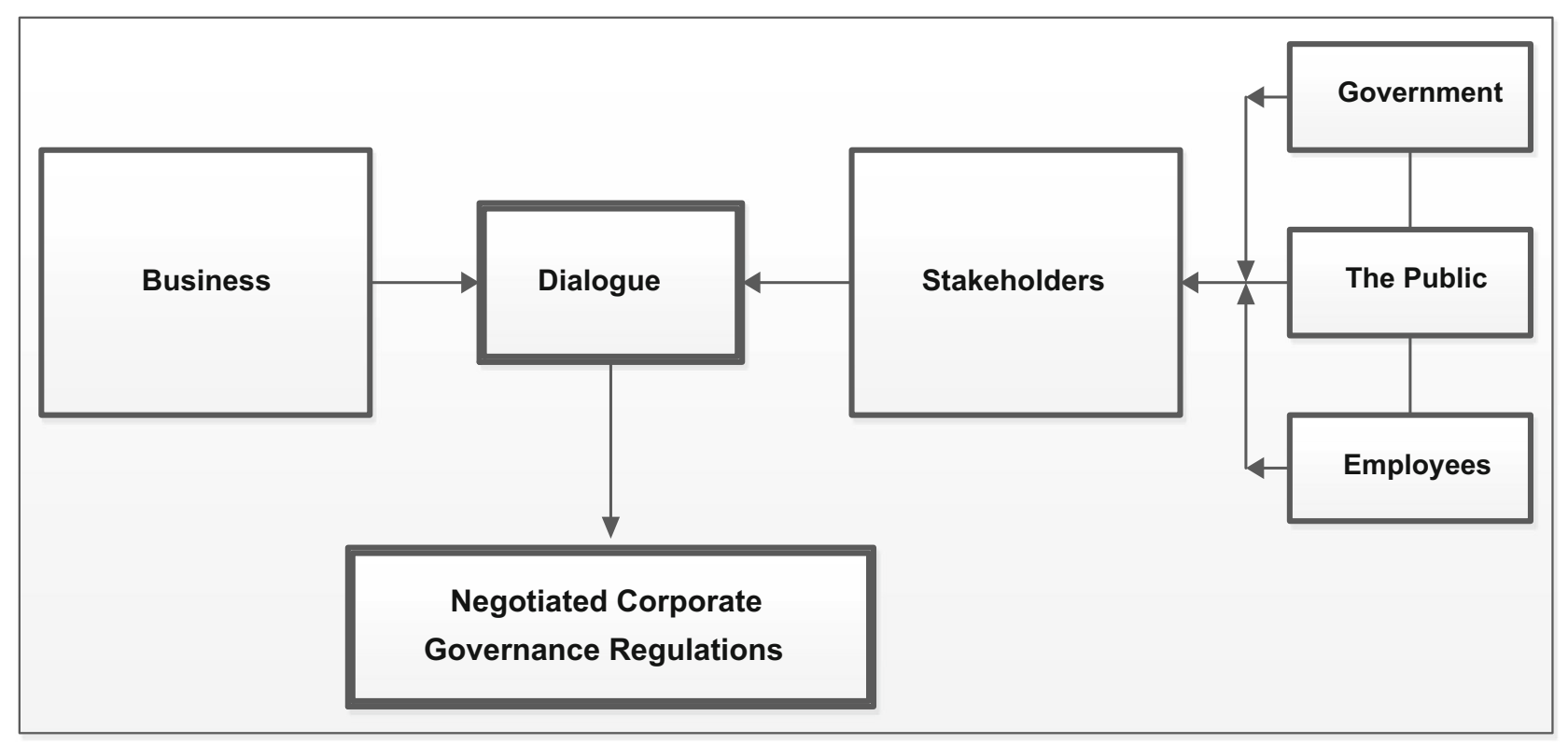

Fig. 3 Multi-stakeholder co-regulation

institutional elements are robust (Arjoon 2005; Tariq and Abbas 2013; Uche et al. 2016). Indeed, as indicated by interviewees, the business environment in Nigeria, as presently constituted, does not support the economic and social sophistication required to accommodate a principlesbased corporate governance regulatory regime. As a result, it was necessary to propose an alternative regulatory strategy for corporate governance in Nigeria to enhance its capacity to engender an effective corporate governance system.

To this effect, an integrated regulatory approach that integrates the appropriate elements of a rule-based and a principle-based approach is proposed. Considering the need to promptly improve corporate governance practice in Nigeria, commencing the new regulatory approach with the rule-based or 'stick approach' (Arjoon 2005) is considered necessary. However, in view of its prior discussed limitations, this approach should be engaged only in the short term. In fact, the approach should be changed as soon as improvements in corporate governance practice are observed. The second (final) stage of implementing the proposed regulation will integrate the principles-based regulatory approach. The efficient mix of appropriate elements of both systems will be subsequently engaged to manage corporate governance in Nigeria, over the long term. We termed this 'the integrated regulatory approach to corporate governance.' This approach allows the principles and rules based regulatory systems to sufficiently reinforce each other to generate optimal outcomes in respect of corporate governance.
To strengthen the application of the integrated regulatory approach, a multi-stakeholder co-regulation was also suggested to enhance corporate governance regulation in Nigeria. The benefits of co-regulation are numerous. It reflects a long-term orientation and allows organisations to better acknowledge the effect of non-compliance on collaborators (Steurer 2013). Furthermore, in a highly dynamic market environment such as Nigeria, co-regulation offers a rapid and flexible response to changes in market conditions. It is also important to state that in view of the confusing provisions in some corporate codes in Nigeria, the use of co-regulation could generate a regulatory framework acceptable to all stakeholders, thus minimising these confusions.

\section{Contributions, Limitations and Future Research}

We make two main contributions. The first proposes an alternative integrated approach for regulating corporate governance in Nigeria. The engagement of an alternative regulatory system for corporate governance not only highlights the variations in institutional environments, but also necessitates a review of the fundamental positions of institutional theory of corporate governance. In Judge et al. (2008), institutions are expected to regulate economic behaviours, as a strategy for building durable corporate governance systems. This framework has been severally adopted to examine the relationship between institutions and corporate governance (Aguilera and Jackson 2003; Filatotchev et al. 2013). 
Unfortunately, this framework might not yield desired outcomes in environments where influential actors in the political and social domains can leverage their resources to create new institutions or transform/influence the functionality of existing ones (Maguire et al. 2004). While this concern is acknowledged in Nigeria, it offers further justification for the need to craft an alternative regulatory regime for corporate governance in the country that has the potential to check the activities of stakeholders in the corporate governance environment. Therefore, despite the view that there is a relationship between weak institutional environments and poor corporate governance regulation (Gourevitch 2003; Estache and Wren-Lewis 2009; Siddiqui 2010), evidence from this paper, taking into account the implementation of the rule-based CBN Code (2006), presents a different outcome.

In essence, there are sparks of good corporate governance practices in regions where this is unexpected. This deserves more attention in future research. Our study takes account of peculiar institutional factors and limitations, and engages the macro- and micro-level issues identified by participants to propose a hybrid framework for corporate governance regulation, inculcating both principles and rules. In doing this, we acknowledge that Nigeria presently lacks the necessary institutional capacity to adopt either a principles-based or a rule-based approach to corporate governance. These approaches are intended to be reinforcing, to enable the corporate governance system in Nigeria to take advantage of both regulatory mechanisms.

Our second contribution recommends co-regulation involving the government and corporations in the country's corporate governance system. The insights we share regarding these are useful in understanding corporate governance regulation in different institutional contexts and help augment the nascent literature on corporate governance in Sub-Saharan Africa. This hybrid co-regulation strategy, involving the state and firms, will aid the accomplishment of a more effective integrated regulation. As a largely government-sector driven economy, regulations have consistently remained the sole preserve of government. This paper demonstrates that increased involvement of organisations in the regulatory development is crucial to improved corporate governance in Nigeria.
In generating our findings, it is necessary to highlight a methodological limitation of this study. We note that data respondents were not drawn from all sectors of the Nigerian economy as classified by the NSE, thereby limiting the extent to which we can generalise the outcomes of this study. However, participants also included consultants who have undertaken various corporate governance-related roles in the economic sectors not represented by participants. As a result, the findings of this study offer significant analytic generalisability (see Yin 2013) in understanding the determinants of corporate governance regulation in different institutional contexts (Adegbite 2015). Nonetheless, future research can rely on a more extensive and representative sample. Finally, it is worth mentioning that governance practices amongst state-owned enterprises (SOEs) have been generally neglected in studies on corporate governance in developing countries, such as Nigeria. This is particularly worrisome as SOEs in Nigeria, for instance, are central to the present state of corporate governance practices (Okike 2007; Kajola 2008). Consequently, future studies may evaluate the regulatory dynamics of corporate governance in SOEs and how it influences the practice of corporate governance in SubSaharan Africa.

\section{Compliance with Ethical Standards}

Ethical Approval All procedures performed in the studies involving human participants were in accordance with the ethical standards of the institutional and/or ethical national research committee and with the 1964 Helsinki declaration and its later amendment or comparable ethical standards.

Informed Consent Informed consent was obtained from all individual participants included in the study.

Open Access This article is distributed under the terms of the Creative Commons Attribution 4.0 International License (http://crea tivecommons.org/licenses/by/4.0/), which permits unrestricted use, distribution, and reproduction in any medium, provided you give appropriate credit to the original author(s) and the source, provide a link to the Creative Commons license, and indicate if changes were made.

\section{Appendix}

See Fig. 4. 
Fig. 4 Thematic framework for study

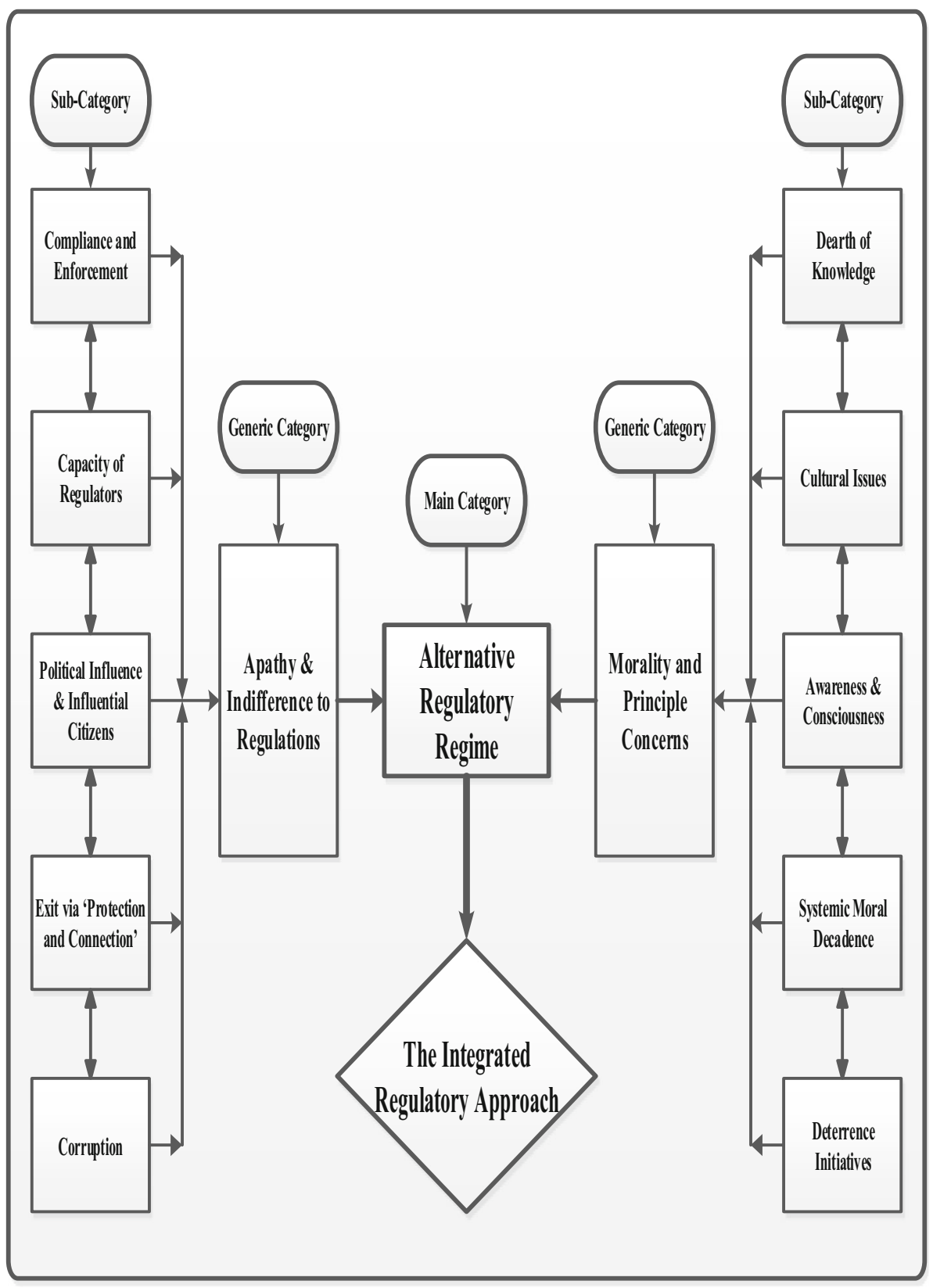

\section{References}

Abdullahi, M., Enyinna, O., \& Ahunanya, S. (2010). Transparency in corporate governance: A comparative study of Enron, USA and Cadbury PLC. Nigeria. The Social Sciences, 5(6), 471-476.

Adegbite, E. (2012). Corporate governance regulation in Nigeria. Corporate Governance, 12(2), 257-276.

Adegbite, E. (2015). Good corporate governance in Nigeria: Antecedents, propositions and peculiarities. International Business Review, 24(2), 319-330.

Adegbite, E., Amaeshi, K., \& Amao, O. (2012). The politics of shareholder activism in Nigeria. Journal of Business Ethics, 105(3), 389-402.

Adegbite, E., Amaeshi, K., \& Nakajima, C. (2013). Multiple influences on corporate governance practice in Nigeria: Agents, strategies and implications. International Business Review, 22(3), 524-538.
Adegbite, E., \& Nakajima, C. (2011). Institutional determinants of good corporate governance: The case of Nigeria. In E. Hutson, R. Sinkovics, \& J. Berrill (Eds.), Firm-level internationalisation, regionalism and globalisation (pp. 379-396). London: Palgrave Macmillan.

Adegbite, E., Shrives, P., \& Nichol, T. (2011). The role of government in corporate governance: Perspectives from the UK. Corporate Ownership and Control, 9(1), 283-293.

Adelopo, I. A., Omoteso, K., \& Obalola, M. (2009). Impact of corporate governance on foreign direct investment in Nigeria. Available at SSRN 1514982.

Adeoye, A. (2009). Macro-economic level corporate governance and FDI in emerging markets: Is there a close relationship? Journal of Economics and International Finance, 1(2), 30-43.

Aguilera, R. V., \& Jackson, G. (2003). The cross-national diversity of corporate governance: Dimensions and determinants. Academy of Management Review, 28(3), 447-465. 
Ahunwan, B. (2002). Corporate governance in Nigeria. Journal of Business Ethics, 37(3), 269-287.

Akers, R. L. (1990). Rational choice, deterrence, and social learning theory in criminology: The path not taken. Journal of Criminal Law and Criminology, 81(3), 653-676.

Albareda, L. (2008). Corporate responsibility, governance and accountability: From self-regulation to co-regulation. Corporate Governance, 8(4), 430-439.

Alesina, A., \& Giuliano, P. (2015). Culture and institutions. Journal of Economic Literature, 53(4), 898-944.

Amaeshi, K. M., Adi, B. C., Ogbechie, C., \& Amao, O. O. (2006). Corporate social responsibility in Nigeria: Western mimicry or indigenous influences? Journal of Corporate Citizenship, 2006(24), 83-99.

Amaeshi, K., \& Amao, O. O. (2009). Corporate social responsibility in transnational spaces: Exploring influences of varieties of capitalism on expressions of corporate codes of conduct in Nigeria. Journal of Business Ethics, 86(2), 225-239.

Amao, O., \& Amaeshi, K. (2008). Galvanising shareholder activism: A prerequisite for effective corporate governance and accountability in Nigeria. Journal of Business Ethics, 82(1), 119-130.

Andreadakis, S. (2008). Research notes: Regulatory or non-regulatory corporate governance-A dilemma between statute and codes of best practice. Journal of Contemporary European Research, 4(3), 253-256.

Apampa, S. (2014). Is there a right corporate governance framework for Nigeria? Premium Times. July 5. Retrieved January 27, 2015. http://www.premiumtimesng.com/opinion/164425-isthere-a-right-corporate-governance-framework-for-nigeria.html.

Arjoon, S. (2005). Corporate governance: An ethical perspective. Journal of Business Ethics, 61(4), 343-352.

Arjoon, S. (2006). Striking a balance between rules and principlesbased approaches for effective governance: A risks-based approach. Journal of Business Ethics, 68(1), 53-82.

Becker, G. S. (1974). Crime and punishment: An economic approach. In G. S. Becker \& M. L. William (Eds.), Essays in the economics of crime and punishment (pp. 1-54). New York: UMI.

Benston, G. J., Bromwich, M., \& Wagenhofer, A. (2006). Principlesversus rules-based accounting standards: The FASB's standard setting strategy. Abacus, 42(2), 165-188.

Berger, P. L., \& Luckmann, T. (1966). The social construction of reality: A treatise in the sociology of knowledge. London: Penguin Books.

Black, J. (2008). Forms and paradoxes of principles-based regulation. Capital Markets Law Journal, 3(4), 425-457.

Black, J., Hopper, M., \& Band, C. (2007). Making a success of principles-based regulation. Law and Financial Market Review, 1, 191-206.

Bräutigam, D. A., \& Knack, S. (2004). Foreign aid, institutions, and governance in sub-Saharan Africa. Economic Development and Cultural Change, 52(2), 255-285.

Bruno, V. G., \& Claessens, S. (2007). Corporate governance and regulation: Can there be too much of a good thing? Policy Research Working Papers.

Bryman, A. (2015). Social research methods (5th ed.). Oxford: Oxford University Press.

Burgemeestre, B., Hulstijn, J., \& Tan, Y.-H. (2009). Rule-based versus principle-based regulatory compliance. In G. Governatori (Ed.), Proceedings of JURIX (pp. 37-46). Amsterdam: IOS Press.

Burmeister, E., \& Aitken, L. M. (2012). Sample size: How many is enough? Australian Critical Care, 25(4), 271-274.

Burnard, P. (1991). A method of analysing interview transcripts in qualitative research. Nurse Education Today, 11(6), 461-466.

Carmona, S., \& Trombetta, M. (2008). On the global acceptance of IAS/IFRS accounting standards: The logic and implications of the principles-based system. Journal of Accounting and Public Policy, 27(6), 455-461.

Cave, J. A. K. (2013). Policy and regulatory requirements for a future internet. In I. Brown (Ed.), Research handbook on governance of the internet. Cheltenham: Edward Elgar.

Cheeseman, N. (2015). Democracy in Africa: Successes, failures, and the struggle for political reform. Cambridge: Cambridge University Press.

Chizema, A. (2008). Institutions and voluntary compliance: The disclosure of individual executive pay in Germany. Corporate Governance: An International Review, 16(4), 359-374.

Denscombe, M. (2010). The good research guide: For small-scale social research projects. New York: McGraw-Hill Education.

Dey, I. (2003). Qualitative data analysis: A user friendly guide for social scientists. London: Routledge.

Djelic, M. L. (1998). Exporting the American model: The post-war transformation of European business. Oxford: Oxford University Press.

Easterby-Smith, M., Thorpe, R., \& Jackson, P. (2012). Management research. London: Sage.

Ellis, A. (2003). A deterrence theory of punishment. The Philosophical Quarterly, 53(212), 337-351.

Elo, S., \& Kyngäs, H. (2008). The qualitative content analysis process. Journal of Advanced Nursing, 62(1), 107-115.

Emenyonu, E. N. (2007). The accounting profession, the church and the Nigerian State: Change agents for national rebirth. Public Lecture given at the Covenant University Ota, Ogun State, Nigeria, June 14.

Estache, A., \& Wren-Lewis, L. (2009). Toward a theory of regulation for developing countries: Following jean-jacques laffont's lead. Journal of Economic Literature, 47(3), 729-770.

Filatotchev, I., \& Boyd, B. K. (2009). Taking stock of corporate governance research while looking to the future. Corporate Governance: An International Review, 17(3), 257-265.

Filatotchev, I., Jackson, G., \& Nakajima, C. (2013). Corporate governance and national institutions: A review and emerging research agenda. Asia Pacific Journal of Management, 30(4), 965-986.

Flick, U. (2014). An introduction to qualitative research. London: Sage.

Glaser, B., \& Strauss, A. (1967). The discovery of grounded theory: Strategies for qualitative research. London: Weidenfield \& Nicolson.

Gourevitch, P. A. (2003). The politics of corporate governance regulation. The Yale Law Journal, 112, 1829-1880.

Guiso, L., Sapienza, P., \& Zingales, L. (2006). Does culture affect economic outcomes? Journal of Economic Perspectives, 20(2), 23-48.

Guiso, L., Sapienza, P., \& Zingales, L. (2009). Cultural biases in economic exchange? The Quarterly Journal of Economics, 124(3), 1095-1131.

Haniffa, R. M., \& Cooke, T. E. (2002). Culture, corporate governance and disclosure in Malaysian corporations. Abacus, 38(3), 317-349.

Hirsch, D. D. (2011). The law and policy of online privacy: Regulation, self-regulation, or co-regulation? Seattle University Law Review., 34, 439-480.

Hofstede, G., Hofstede, G. J., \& Minkov, M. (2010). Cultures and organizations: Software of the mind ( $3 \mathrm{rd}$ ed.). New York: McGraw Hill.

Hsieh, H.-F., \& Shannon, S. E. (2005). Three approaches to qualitative content analysis. Qualitative Health Research, 15(9), 1277-1288.

Institute of Directors SA. (2009). King code of governance for South Africa. Retrieved February 18, 2015. http://c.ymcdn.com/sites/ www.iodsa.co.za/resource/collection/94445006-4F18-4335-B7F 
B-7F5A8B23FB3F/King_Code_of_Governance_for_SA_2009_ Updated_June_2012.pdf.

Inyang, B. J. (2009). Nurturing corporate governance system: The emerging trends in Nigeria. Journal of Business Systems, Governance and Ethics, 4(2), 1-13.

Ite, U. E. (2004). Multinationals and corporate social responsibility in developing countries: A case study of Nigeria. Corporate Social Responsibility and Environmental Management, 11(1), 1-11.

Judge, W. Q., Douglas, T. J., \& Kutan, A. M. (2008). Institutional antecedents of corporate governance legitimacy. Journal of Management, 34(4), 765-785.

Just, N., \& Latzer, M. (2004). Self-and co-regulation as indicators of a transformed statehood. In S. P. Reikmann, M. Mokre, \& M. Latzer (Eds.), The State of Europe: Transformation of statehood from a European perspective (pp. 266-286). Frankfurt/New York: Campus.

Kajola, S. O. (2008). Corporate governance and firm performance: The case of Nigerian listed firms. European Journal of Economics, Finance, and Administrative Sciences, 14, 16-28.

Kim, D., \& Saito, M. (2009). A rule-based medium-term fiscal policy framework for Tanzania. Washington, DC: International Monetary Fund.

Kirkbride, J., \& Letza, S. (2004). Regulation, governance and regulatory collibration: Achieving an "holistic" approach. Corporate Governance: An International Review, 12(1), 85-92.

Kraatz, M. S., \& Zajac, E. J. (1996). Exploring the limits of the new institutionalism: The causes and consequences of illegitimate organizational change. American Sociological Review, 61(5), 812-836.

Licht, A. N., Goldschmidt, C., \& Schwartz, S. H. (2005). Culture, law, and corporate governance. International Review of Law and Economics, 25(2), 229-255.

Lubatkin, M., Lane, P. J., Collin, S., \& Very, P. (2007). An embeddedness framing of governance and opportunism: Towards a cross-nationally accommodating theory of agency. Journal of Organizational Behavior, 28(1), 43-58.

Madhani, P. M. (2007). Corporate governance: A journey from compliance to competitive advantage. In R. K. Jain, P. Gupta, \& U. Dhar (Eds.), Enhancing enterprise competitiveness (strategy, operations and finance) (pp. 19-33). New Delhi: Allied Publishers.

Maguire, S., Hardy, C., \& Lawrence, T. B. (2004). Institutional entrepreneurship in emerging fields: HIV/AIDS treatment advocacy in Canada. Academy of Management Journal, 47(5), $657-679$

Mangena, M., Tauringana, V., \& Chamisa, E. (2012). Corporate boards, ownership structure and firm performance in an environment of severe political and economic crisis. British Journal of Management, 23(S1), S23-S41.

Mason, M. (2010). Sample size and saturation in PhD studies using qualitative interviews. Forum: Qualitative. Social Research,. doi: $10.1177 / 1468794107085301$.

Mayring, P. (2000). Qualitative content analysis. Forum: Qualitative. Social research,. doi:10.1177/1049732305276687.

Munene, J. C. (1995). The institutional environment and managerial innovations: A qualitative study of selected Nigerian firms. Journal of Occupational and Organizational Psychology, 68(4), 291-300.

Odeleye, A. T. (2014). Pre-consolidation and post-consolidation of Nigerian banking sector: A dynamic comparison. International Journal of Economics and Financial Issues, 4(1), 27-34.

OECD. (1999). OECD principles of corporate governance. Ad hoc task force on corporate governance. Paris: Organisation for Economic Co-operation and Development.

OECD. (2004). OECD principles of corporate governance. http:// www.oecd.org/corporate/ca/corporategovernanceprinciples/3155 7724.pdf.
Ofo, N. (2010). Corporate governance in Nigeria: Prospects and problems. Retrieved April 27, 2013. http://papers.ssrn.com/sol3/ papers.cfm?abstract_id $=1618600$.

Ofo, N. (2011). Code of corporate governance in Nigeria 2011: Its fourteen fortes and faults. Retrieved August 29, 2013. http:// papers.ssrn.com/sol3/papers.cfm?abstract_id=1937896.

Oghojafor, B., George, O., \& Owoyemi, O. (2012). Corporate governance and national culture are siamese twins: The case of Cadbury (Nigeria) Plc. International Journal of Business and Social Science, 3(15), 269-278.

Okeahalam, C. C., \& Akinboade, O. A. (2003). A review of corporate governance in Africa: Literature, issues and challenges. Paper presented at the Global Corporate Governance Forum.

Okike, E. N. (2007). Corporate governance in Nigeria: The status quo. Corporate Governance: An International Review, 15(2), 173-193.

Okike, E., \& Adegbite, E. (2012). The code of corporate governance in Nigeria: Efficiency gains or social legimitation? Corporate Ownership and Control, 95(3), 262-275.

Okpara, J. (2010). Perspectives on corporate governance challenges in a sub-Saharan African economy. Journal of Business and Policy Research, 5(1), 110-122.

Okpara, J. (2011). Corporate governance in a developing economy: Barriers, issues, and implications for firms. Corporate Governance, 11(2), 184-199.

Osemeke, L., \& Adegbite, E. (2016). Regulatory multiplicity and conflict: Towards a combined code on corporate governance in Nigeria. Journal of Business Ethics, 133(3), 431-451.

Oyadonghan, K. J., \& Ogiriki, T. (2014). Information asymmetry and environmental accounting: An empirical view. International Journal of Managerial Studies and Research, 2(7), 101-116.

Patton, M. Q. (2002). Qualitative evaluation and research methods (3rd ed.). Newbury Park, CA: Sage.

Polit, D. F., \& Beck, C. T. (2012). Nursing research: Principles and methods (8th ed.). Philadelphia, PA: Lippincott Williams \& Wilkins.

Pope, C., Ziebland, S., \& Mays, N. (2000). Qualitative research in health care: Analysing qualitative data. British Medical Journal, $320,114-116$.

Roe, M. J. (2003). Political determinants of corporate governance: Political context, corporate impact. Oxford: Oxford University Press.

ROSC. (2004). Report on the Observance of Standards and Codes (ROSC). Retrieved May 3, 2013. http://www.worldbank.org/ifa/ rosc_aa_nga.pdf.

Rwegasira, K. (2000). Corporate governance in emerging capital markets: Whither Africa? Corporate Governance: An International Review, 8(3), 258-267.

Sama, L. M., \& Shoaf, V. (2005). Reconciling rules and principles: An ethics-based approach to corporate governance. Journal of Business Ethics, 58(1), 177-185.

Schreier, M. (2012). Qualitative content analysis in practice. London: Sage.

Schwarcz, S. L. (2009). The 'principles' paradox. European Business Organization Law Review, 10(2), 175-184.

Scott, W. R. (2014). Institutions and organizations: Ideas, interests and identities. Los Angeles: Sage.

Seidman, D. (2004). The essential union of law and ethics. Bentley College, MA: Ethics Matters.

Shrives, P. J., \& Brennan, N. M. (2015). A typology for exploring the quality of explanations for non-compliance with UK corporate governance regulations. The British Accounting Review, 47(1), $1-15$.

Siddiqui, J. (2010). Development of corporate governance regulations: The case of an emerging economy. Journal of Business Ethics, 91(2), 253-274. 
Solomon, J. (2013). Corporate governance and accountability (4th ed.). Chichester: Wiley.

Soludo, C. C. (2006). Beyond banking sector consolidation in Nigeria. Paper presented at the global banking conference on Nigerian Banking Reforms. The Dorchester Hotel, London.

Steurer, R. (2013). Disentangling governance: A synoptic view of regulation by government, business and civil society. Policy Sciences, 46(4), 387-410.

Stigliani, I., \& Ravasi, D. (2012). Organizing thoughts and connecting brains: Material practices and the transition from individual to group-level prospective sensemaking. Academy of Management Journal, 55(5), 1232-1259.

Suddaby, R. (2010). Challenges for institutional theory. Journal of Management Inquiry, 19(1), 14-20.

Sun, N., Salama, A., Hussainey, K., \& Habbash, M. (2010). Corporate environmental disclosure, corporate governance and earnings management. Managerial Auditing Journal, 25(7), 679-700.

Tabellini, G. (2008). Institutions and culture. Journal of the European Economic Association, 6(2-3), 255-294.

Tabellini, G. (2010). Culture and institutions: Economic development in the regions of Europe. Journal of the European Economic Association, 8(4), 677-716.
Tariq, Y. B., \& Abbas, Z. (2013). Compliance and multidimensional firm performance: Evaluating the efficacy of rule-based code of corporate governance. Economic Modelling, 35, 565-575.

Trevino, L. K., \& Nelson, K. A. (2010). Managing business ethics: Straight talk about how to do it right (5th ed.). New York: Wiley.

Tricker, B. (2015). Corporate governance: Principles, policies and practices (3rd ed.). Oxford: Oxford University Press.

Uche, C. O., Adegbite, E., \& Jones, M. (2016). Institutional shareholder activism in Nigeria: An accountability perspective. Accounting Forum. doi:10.1016/j.accfor.2016.03.001.

Weber, R. P. (1990). Basic content analysis (2nd ed.). London: Sage.

Witt, M., \& Redding, G. (2009). Culture, meaning and institutions: Executive rationale in Germany and Japan. Journal of International Business Studies, 40(5), 859-885.

Yakasai, A. G. (2001). Corporate governance in a third world country with particular reference to Nigeria. Corporate Governance: An International Review, 9(3), 238-253.

Yin, R. K. (2013). Case study research: Design and methods (5th ed.). Thousand Oaks, CA: Sage. 